\begin{tabular}{|c|l|}
\hline Title & $\begin{array}{l}\text { An optical telemetry system for underwater recording of electromy ogram and neuronal activity from non-tethered } \\
\text { crayfish }\end{array}$ \\
\hline Author(s) & Tsuchida, Y oshikazu; Hama, Noriy uki; Takahata, Masakazu \\
\hline Citation & $\begin{array}{l}\text { Journal of Neuroscience Methods, 137(1), 103-109 } \\
\text { https:/doi.org/10.1016/.jneumeth.2004.02.013 }\end{array}$ \\
\hline Issue Date & 2004 08-15 \\
\hline Doc URL & http:/hdl.handle.net/2115/16955 \\
\hline Type & article (author version) \\
\hline File Information & JNM137-1.pdf \\
\hline
\end{tabular}

Instructions for use 


\title{
An optical telemetry system for underwater recording of electromyogram and neuronal activity from non-tethered crayfish
}

\author{
Yoshikazu Tsuchida ${ }^{1}$, Noriyuki Hama ${ }^{2}$ and Masakazu Takahata ${ }^{2}$ \\ ${ }^{1}$ Research Institute for Electronic Science, Hokkaido University, Sapporo 060-0812, \\ Japan \\ ${ }^{2}$ Animal Behavior and Intelligence, Division of Biological Sciences, Graduate School \\ of Science, Hokkaido University, Sapporo 060-0810, Japan
}

Number of pages: $\quad 30$

Number of figures: $\quad 6$

Key words: underwater telemetry, optical telemetry, neuronal activity, muscle potential, crayfish

*Corresponding author

Tel: $\quad+81-11-706-2753$

Fax: $\quad+81-11-706-4923$

E-mail: hnori@sci.hokudai.ac.jp 


\section{Abstract}

We developed an optical telemetry system for recording electrical signals associated with muscle and neuronal activities from freely walking crayfish under water. The device was made from conventional electronic parts commercially available, utilizing infrared light $(880 \mathrm{~nm})$ for signal transmission. Two or four channels of biological signals were multiplexed, the voltage of each data point modulated to the duration of subcarrier pulses and further to the interval of narrower carrier pulses that directly drove the infrared light emission diode (IRLED) under water. The light-pulse modulated signals were received by photodiodes and demodulated to restore the original 2 or 4 channel signals. Electrical recordings using wired electrodes and conventional amplifiers revealed that the optically transmitted signals were consistent with the wire-transmitted ones. In order to test the performance of this system, we recorded electromyograms (EMGs) from the 2nd and 3rd walking legs on each side of crayfish, together with the neuronal activity in the ventral nerve cord. The result confirmed our previous observation obtained in tethered crayfish that the background tonus of leg muscles showed an increase preceding to their rhythmic activation. 


\section{Introduction}

Electrophysiological techniques for recording muscle and neural activities from

freely behaving animals are essential to understandings of the neuronal mechanism controlling animal behavior. Radio telemetry systems have been extensively used for biological signal recording from freely behaving animals on the ground and in the air (Albright et al., 1967; Mackey, 1970; Fisher et al., 1996; Ando et al., 2002). In underwater condition, however, radio transmission has been impracticable for telemetry of electromyographic and neural signals due to high conductivity of water (Stasko and Pincock, 1977; Winter et al., 1984; Sisak and Lotimaer, 1998). Kudo et al. (1999) developed an underwater antenna system for radio telemetry to transmit electroencephalographic signals from freely swimming fish. Their telemetry system could transmit signal ranging $1-40 \mathrm{~Hz}$, just enough for electroencephalographic studies but not for acquiring neuronal signals, in particular, spike activities.

An alternative medium for underwater telemetry in lieu of radio wave is light.

The optical wave does attenuate in water as radio wave, but its transmission in freshwater and seawater is relatively stable because the extinction coefficient of the 
optical wave for water is relatively low (Hale and Querry, 1973). The frequency range for optical transmission can be made wider than that for radio wave transmission so that fast biological signals such as spikes can be transmitted with a high fidelity.

Another problem in addition to the frequency response regarding underwater telemetry is the size of transmitter. Using common electric parts that are commercially available, downsizing of the transmitter has an inevitable limitation. We have been studying neurophysiological mechanisms underlying the behavioral context-dependent control of body posture during locomotion in crayfish (Yoshino et al., 1980; Takahata et al., 1984). The subject has long drawn the attention of many investigators using many other freshwater and marine crustaceans (Davis, 1968; Sandeman, 1978; Fraser, 1990). A useful telemetry system is vitally needed to push forward with further research on the subject as well as other behaviors of underwater animals. Our preliminary trial revealed that it would be possible to make a transmitter with the size small enough for crayfish and other large crustaceans using commercially available electric parts and batteries. After making several trials, we could complete a wholly new optical telemetry system for practical use with underwater animals. 
In this paper, we report the technological details of the optical telemetry system together with the results of comparison experiments using both the newly developed system and conventional wired recording techniques applied for electromyographic and neural activity recording in crayfish. We also discuss the physiological significance of some of the data acquired in this study using the new optical telemetry system in freely moving crayfish under water. 


\section{Materials and methods}

\subsection{Animals and preparation}

Adult crayfishes Procambarus clarkii, 10 - $12 \mathrm{~cm}$ in body length and $1.6-2.0$

cm in carapace width and Pacifastacus leniusculus, $11-12 \mathrm{~cm}$ and $2.0-2.5 \mathrm{~cm}$ respectively, of both sexes were used. They were commercially obtained and kept in laboratory tanks. The transmitter was mounted on the ventral side of the carapace and fixed to the cuticular surface with adhesive (Fig. 1A and B). The weight of dual- and quad-channel transmitters coated with silicon for insulation was $13 \mathrm{~g}$ and $16.2 \mathrm{~g}$ respectively, including 2 button batteries (CR2032). The quad-channel transmitter was larger in volume than the dual-channel transmitter (Table-1). Due to its larger volume, the quad-channel transmitter could be used with P. clarkii. The transmitter was always $\underline{\text { used with P. leniusculus. For recording of electromyograms (EMGs) from the putative }}$ mero-carpopodite flexor muscle, a pair of Teflon-coated silver wires (125 $\mu \mathrm{m}$ in diameter) was inserted to the cuticle of the anterior side of the meropodite. The musculature arrangement of meropodite was so complex (Bush et al., 1978) that exact identification of the recorded muscle was difficult. Although we tentatively identified 
the recorded muscle as the meropodite flexor muscle based on the site of electrode insertion through the cuticle, the recording contamination could not be avoided completely: activities of other meropodite muscles, including the extensor and accessory flexor muscles, were concurrently recorded with the flexor activities in some experiments. The same silver wires were used for chronic recording of spike activities from the circumesophageal connective. The electrode was inserted into the body cavity through a small hole ( $5 \mathrm{~mm} \times 5 \mathrm{~mm}$ ) on the dorsal side of the cephalothorax. The location of the electrode was visually monitored and adjusted to the circumesophageal connective. Removed cuticle was put on the hole again and fixed by adhesive. Recordings from the circumesophageal connective were made from resting animals that could move freely. A schematic diagram of the experimental set up for simultaneous underwater recording from four walking legs is shown in Fig. 1C.

\subsection{Transmitter}

We used modified pulse duration modulation/pulse interval modulation (modified PDM/PIM) for multi-channel recording of muscle and neural activities. 
Electrical circuits of preamplifiers for each channel and the multiplexed signal modulator/transmitter unit are shown in Fig. 2. The unit consisted of four preamplifiers, a distributor, counter, subcarrier modulator, main carrier modulator and a power regulator. Each preamplifier was made of low-dissipation CMOS analog ICs as a differential amplifier with the bandwidth of 0.15 - 8.7 kHz. Signals from four amplifiers were multiplexed using a high-speed Si-gate CMOS IC (74HC4052, Toshiba, Tokyo) at the switching frequency of around $28 \mathrm{kHz}$ supplied by a JK-type flip-flop counter (74HC107). A free-running multivibrator made from 2 monostable multivibrators (TC4538, Toshiba, Tokyo) provided a square wave in which the amplitude of each sample point in the multiplexed signal was encoded to the duration of pulses as the subcarrier signal having either high or low state (pulse duration modulation; PDM): the first high-state pulse encoded the amplitude of the first channel, the first low-state pulse that of the second and so on in the quad-channel transmitter (Matsumoto et al., 1980). In the dual-channel transmitter, both the analog multiplexer and the counter for channel distribution were obviated so that the circuit became simpler and lighter. The duration time of the channel 1 pulse was $3 \mu$ s longer than other 3 channels for synchronization. 
The main carrier modulator generated short duration pulses ( 4 us for 1 and 3 channel, 2

$\mu$ for 2 and 4 channel) at the edges of the high and low levels of the subcarrier square wave so that the pulse-duration-coded signal amplitude was further coded into the intervals of main carrier pulses having shorter duration (pulse interval modulation; PIM). These PIM signals drove infrared light emission diode (IRLED; 880 nm, CL-1CL3, Kodenshi Corp.) with less power dissipation than PDM signals. Two lithium batteries (3V, CR2032) were used as power supplier for the circuit and IRLED. The circuit was mounted on an aluminum plate coated with acrylic resin and embedded in polyurethane, two lithium batteries coated with silicon, to make the whole transmitter waterproof.

\subsection{Receiver and PPM de-modulation}

The receiver/demodulating circuit is shown in Fig. 3. PIM signals from the transmitter were received by four PIN-photodiodes (S6967-01, Hamamatshu photonics) having faster response characteristics than conventional photodiodes and phototransistors. We placed each PIN-photodiode in water $(1 \mathrm{~cm}$ depth) at each corner of the tank filled with water to the depth of $12 \mathrm{~cm}$ : the photodiodes were $11 \mathrm{~cm}$ above 
the tank bottom (Fig. 1C). Received PIM current signals were converted to voltage signals by a current-voltage converter and then demodulated to analog signals by reverse processes of PDM/PIM modulation: PIM signals were demodulated to PDM signals and then to analog multiplexed signals that were further demodulated into 4 channels of analog data by a demultiplexor (Fig. 3). The analog signals were fed into a digital audio tape recorder (TEAC, RD-135T) and, at the same time, converted to digital data using an A/D converter (Power Lab, ADInstruments) and software (Chart v4.2, ADInstruments). The transmitter could continuously work for more than 4 hours without changing batteries. 


\section{Results}

\subsection{Comparison with wired recordings}

In order to test the performance of our optical telemetry system regarding the bandwidth and signal-to-noise ratio, we compared the optical recordings with those obtained by a conventional wired system using a differential amplifier commercially available for biological use (MEG-1000, Nihon Kohden; bandwidth selected to 0.15 - 1 $\mathrm{kHz}$ ). A pair of wire electrodes was implanted into the putative mero-carpopodite flexor muscle or the circumesophageal commissure of Procambarus clarkii, and for comparison, Pacifastacus leniusculus. The electrodes were simultaneously coupled to the wired system and to the transmitter by soldering followed by enamel-coat insulation. EMGs and spike activities recorded by the 2 methods are compared in Fig. 4.

Visual observation of these records shows that the recording quality for the EMG is comparable between the wired and optical transmission recording (Fig. 4A 1 ). In order to compare these records quantitatively, we carried out the Fourier analysis using the conventional FFT algorithm (Chart v4.2, ADInstrument) with the Hanning window function. The power spectra thus obtained were also comparable in the bandwidth and 
maximal power frequency (Fig. $4 \mathrm{~A}_{2}$ ). Each spectrum was normalized to the maximal noise power for comparison. On the other hand, the recording of spike activity obtained by the optical telemetry system had a higher noise level than that by the conventional amplifier system (Fig. 4B $\mathrm{B}_{1}$ ). The noise amplitude was about $\pm 3 \mu \mathrm{V}$ in the optical transmission whereas it was about $\pm 0.8 \mu \mathrm{V}$ in the wired transmission. Due to such a high noise amplitude, it was difficult in the optical telemetry system to clearly discriminate the smaller amplitude spikes that could be unambiguously distinguished in the wired transmission. The frequency analysis by FFT supported this observation. The bandwidth of the optical telemetry recording system was wider than that of the wire-coupled recording system while the maximal power frequency remained almost the same. Since the amplitude of neuronal signals was smaller than that of EMG, the amplification gain had to be higher than EMG recording in both types of recording system. The high amplitude of baseline noise in the optical telemetry system was due to limited specification of the pre-amplifier used in the transmitter.

\subsection{Muscle activity recording during free underwater walking}


As described above, comparison of recordings obtained by optical and wired transmission revealed that our telemetry system could transmit both EMG and spike signals with physiological adequacy. In the present study, we applied the telemetry system to simultaneous recording of EMGs from walking legs of freely behaving crayfish under the water. In both tethered and non-tethered conditions, the leg movements during walking have been intensively analyzed both behaviorally and physiologically (Ayers and Davis 1977; Jamon and Clarac 1994; Domenici et al. 1998). For understanding the neuronal mechanism underlying the initiation of walking in natural conditions, however, it remains to be undertaken to record and analyze the activity changes of leg muscles at the onset of walking in non-tethered animals. We made simultaneous EMG recordings from the meropodite of the 2nd and 3rd walking legs on both sides. Since the muscle arrangement in the meropodite is not very simple, it was difficult to determine from which muscle the recording was made. In the present study, we tentatively identified the recorded muscle to be the mero-carpopodite flexor (MCF) based on the site of electrode insertion through the cuticle.

Typical EMGs recorded simultaneously from the MCF of four legs using the 
optical telemetry system are shown in Fig. 5A. Before walking, the MCF showed low activity in all legs. At the onset of the walking, the burst activity for stepping was preceded by an increase of muscle activity in all legs. The EMG records shown in Fig. $\underline{5 \mathrm{~A} \text { are partly expanded in Fig. } 5 \mathrm{~B} \text { to show the muscle activity in more detail. It was }}$ noted here that the tonic increase of muscle activity preceded the onset of stepping which occurred simultaneously in all four walking legs. The increase in muscle activity preceding to stepping behavior and postural reflexes was also observed in wired recording from freely walking crayfish (Takahata et al., 1984). 


\section{Discussion}

In behavioral and physiological studies that require wireless transmission of biological signals, the radio telemetry system has so far been widely adopted (Albright et al., 1967; Mackey, 1970; Fisher et al., 1996; Ando et al., 2002). Under the water, however, the high conductivity of water raises a high propagation loss making the underwater radio telemetry practically difficult (Stasko and Pincock, 1977; Winter et al., 1984; Sisak and Lotimaer, 1998). In this study, we newly developed an underwater optical telemetry system for neurophysiological studies that could be used not only with crayfish and larger crustaceans but also with vertebrates of small sizes including fish, frog and reptiles. As can be seen in Table 1, our optical telemetry system has sufficient specifications for underwater recording of biological signals. When compared with conventional telemetry systems, especially the radio telemetry system, the optical telemetry system can make more stable recording than radio telemetry system due to the use of light as the main carrier. On the other hand, the optical telemetry system has a disadvantage in its voluminous size, although the radio telemetry system would have the same disadvantage if it is to be made from conventional electronic parts commercially 
available. Major points to be discussed here concern to what degree the transmitter interferes with the free behavior of the animal and to what extent it can be used practically.

Our telemetry system was originally developed for use with crayfish. The weight of the dual- and quad-channel transmitter under the water was $9 \mathrm{~g}$ and $6.2 \mathrm{~g}$, respectively including batteries, corresponding approximately to $20 \%$ of the animal weight. It has been reported that hawkmoth could freely fly when the moth was equipped with a microtransmitter weighing $20 \%$ of the body weight (Ando et al., 2002). It would be safe to assume that our transmitter would also not prevent crayfish from walking around freely. The retention time of the lithium battery presently used was more than 4 hours. Use of smaller batteries would reduce the total weight of the transmitter although the recording time becomes shorter accordingly.

In this study, we placed a photodiode at each corner of the experimental aquarium (30 cm width $\times 40 \mathrm{~cm}$ depth $\times 15 \mathrm{~cm}$ height). This experimental area was not limited by signal extinction: we could record the signal wherever the animal was in this aquarium. We tested how far the signal could be transmitted using a larger aquarium and 
confirmed that the signal was receivable at $50 \mathrm{~cm}$ from the transmitter. For transmission over longer distance, some modification of this system would be needed. Using the same transmitter, the number of photodiodes can be effectively increased to expand the experimental area. Changing the main carrier wavelength will be also effective: extinction of light having the wavelength of $625 \mathrm{~nm}$, for example, is less than that of $880 \mathrm{~nm}$ (Hale and Querry, 1973). In this case, it should be noted that the visual pigments of crustaceans are sensitive to light having the wavelength shorter than 600 $700 \mathrm{~nm}$, the wavelength for maximal physiological sensitivity ranging from 505 to 570 nm (Goldsmith, 1972). 


\section{Acknowledgements}

We are grateful to Prof. Shimozawa and the members of Laboratory of

Neuro-Cybernetics for their kind help in carrying out this study. This work was

supported in part by grants (No. 14340260, 14918001, 15657018) from the Ministry of

Education, Science, Culture and Sports, Japan. 


\section{References}

Albright CD, McGarry WP, Ott OJ. Runyan, R.A., FM-FM telemetry system. In Gurenberg EL, editor. Handbook of Telemetry and Remote Control. New York: Mcgraw Hill. 1967;Chapter. 6:1-62.

Ando N, Shimoyama I, Kanzaki R. A dual-channel FM transmitter for acquisition of flight muscle activities from the freely flying hawkmoth, Agrius convolvuli. J. Neurosci. Methods 2002;115:181-187.

Ayers JL, Davis WJ. Neuronal control of locomotion in the lobster, Homarus americanus. J. Com. Physiol. 1997;115:1-27.

Bush BMH, Vedel JP, Clarac F. Intersegmental reflex actions from a joint sensory organ (CB) to a muscle receptor (MCO) in decapod crustacean limb. J. Exp. Biol. 1978; 73:47-63.

Bowerman RF, Larimer JL, Command fibers in the circumesophageal connectives of crayfish II. Phasic fibers. J. Exp. Biol. 1974;60:119-134.

Domenici P, Jamon M, Clarac F. Curve walking in freely moving crayfish (Procambarus clarkii). J. Exp. Biol. 1998; 201:1315-1329. 
Fisher H, Kautz H, Kutsch W. A radiotelemetric 2-channel unit for transmission of muscle potentials during free flight of the desert locust, Schistocerca gregaria. J. Neurosci. Methods 1996; 64:39-45.

Fraser PJ, Equilibrium control by statocyst activated interneurones. In Wiese K, Krenz W-D, Tautz J, Reichert H, Mulloney B, editors. Frontiers in Crustacean Neurobiology. Basel: Birkhäuser Verlag. 1990; 187-192.

Goldsmith TH, The natural history of invertebrate visual pigments. In Dartnall HJA, editor. Handbook of Sensory Physiology Vol. VII/1 Photochemistry of Vision. Berlin: Springer Verlag. 1972; 685-719.

Hale GM, Querry MR. Optical constants of water in the 200-nm to 200- $\mu$ m wavelength region. Applied Optics 1973; 12:555-563.

Jamon M, Clarac F. Locomotor patterns in freely moving crayfish (Procambarus clarkii). J. Exp. Biol. 1994;198:683-700.

Kudo Y, Satou M, Kitamura S, Iwata M, Takeuchi Y. A newly designed underwater antenna and its application to underwater radio-telemetry for measuring electroencephalographic activity from rainbow trout freely swimming in natural 
environments. Frontiers Med. Biol. Engng. 1999; 9:285-294.

Mackey RS, Bio-medical Telemetry. John Wiley. New York. 1970

Matsumoto G, Kuriki Y, Tshichida Y, Furukawa T. Measurement of the cat's EEG and ECG with a telemetry system in high DC electric fields. I. A two-channel modified PDM/FM telemetry system to obtain data from small animals. In Matshumoto G, Kimmich HP. editors. Biotelemetry V. Sapporo: 1980; 141-144.

Sandeman DC. Eye-scanning during walking in the crab Leptograpsus variegatus. J. Comp. Physiol. A. 1978; 249-257.

Sisak MM, Lotimaer JS. Frequency choice for radio telemetry: the HF vs. VHF conundrum. Hydrobiologia 1998; 371/372: 53-59.

Stasko A. Pincock DG. Review of underwater biotelemetry, with emphasis on ultrasonic techniques. J. Fish. Res. Bd. Can. 1977; 34:1261-1285.

Takahata M, Komatsu H, Hisada M. Positional orientation determined by the behavioural context in Procambarus ckarkii Girard (Decapoda: Macrura). Behaviour 1984; 88:240-265.

Winter JD, Ross MJ, Kuechle VB. Applications of radiotelemetry to studies on 
free-ranging aquatic animals. In Kimmich HP, Klewe HJ, editors. Biotelemetry VIII. Braunschweig: Döring-Druck, Druckerei und Verlag. 1984; 391-395. 


\section{Figure legends}

Table 1. Specifications of dual- and quad-channel transmitters.

Figure 1. Photographs of dual- $\left(\mathrm{A}_{1}\right)$ and quad-channel $\left(\mathrm{A}_{2}\right)$ transmitters, and a schematic drawing of their appearance after mounted on crayfish (B). Each transmitter was fixed on the cephalothorax of crayfish with adhesive not to restrain normal movements of the walking legs. (C) Experimental set up for simultaneous underwater recording from four walking legs in a freely behaving crayfish. Four PIN photodiodes (PDs) were placed in water at each corner of the experimental aquarium $(30 \mathrm{~cm}$ width $\times$

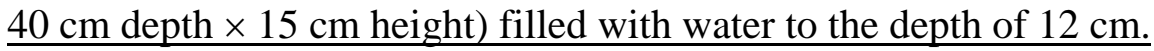

Figure 2. Circuit diagrams of the quad-channel transmitter which consisted of 4 pre-amplifiers, a power supplier and an analog/PDM/PIM modulator. The same type of pre-amplifier was used for all four channels. Each of two button batteries was used for activation of the circuit and IRLED activation respectively. 
Figure 3. Electrical circuits of the de-modulator, amplifier and offset adder.

Figure 4. Comparison of EMG activities (A) and neuronal activities (B) recorded by a wire-coupled conventional amplifier and by the optical telemetry system. In $\mathrm{A}_{1} \underline{\text { and }}_{\mathrm{B}_{1}}$ upper traces are recordings obtained by the conventional amplifier and bottom traces obtained by the optical telemetry system. Left panels in $\mathrm{A}_{2}$ and $\mathrm{B}_{2} \underline{\text { show }}_{2}$ the power spectra of the record obtained by a wire-coupled amplifier. Right panels in $\mathrm{A}_{2} \underline{\text { and }} \mathrm{B}_{2}$ are the power spectra of the optically transmitted record. They are normalized to the maximal noise power for comparison.

Figure 5. EMG activities of four walking legs at the onset of walking. EMG recordings were simultaneously obtained from four walking legs. At the onset of walking, the EMG activity of all four legs showed an increase and then proceeded to rhythmic bursts for stepping movements (A). The activities are expanded around the onset time of walking behavior (B). 


\begin{tabular}{|c|c|c|c|}
\hline & & $\begin{array}{c}\text { 2ch } \\
\text { transmitter }\end{array}$ & $\begin{array}{c}\text { 4ch } \\
\text { transmitter }\end{array}$ \\
\hline \multicolumn{2}{|l|}{ Main carrier: } & $880 \mathrm{~nm}$ (infrared) & $880 \mathrm{~nm}$ (infrared) \\
\hline \multicolumn{2}{|l|}{ Sampling frequency: } & $26.7 \pm 3.5 \mathrm{kHz}$ & $14 \pm 2.5 \mathrm{kHz}$ \\
\hline \multirow[t]{2}{*}{ Total power consumption: } & Circuits & $1.98 \mathrm{~mW}$ & $6.8 \mathrm{~mW}$ \\
\hline & LED & $27 \mathrm{~mW}$ & $36 \mathrm{~mW}$ \\
\hline \multirow[t]{2}{*}{ Supply voltage: } & Circuits & $3 \mathrm{~V}$ & $3 \mathrm{~V}$ \\
\hline & LED & $3 \mathrm{~V}$ & $3 \mathrm{~V}$ \\
\hline \multicolumn{2}{|l|}{ Battery retention time: } & $6 \mathrm{hrs}$ & $4 \mathrm{hrs}$ \\
\hline \multicolumn{2}{|c|}{ Frequency range of input signal: } & $150 \mathrm{~Hz}-8.7 \mathrm{kHz}$ & $150 \mathrm{~Hz}-8.7 \mathrm{kHz}$ \\
\hline \multicolumn{2}{|l|}{ Input impedance: } & $1000 \mathrm{M} \Omega$ & $1000 \mathrm{M} \Omega$ \\
\hline \multirow{2}{*}{\multicolumn{2}{|c|}{ Gain of input amplifier: }} & $67.6 \mathrm{~dB}$ & $64.8 \mathrm{~dB}(1 \mathrm{ch})$ \\
\hline & & & $67.4 \mathrm{~dB}(2,3,4 \mathrm{ch})$ \\
\hline \multicolumn{2}{|l|}{ Maximum input voltage: } & $\pm 250 \mu \mathrm{V}$ & $\pm 250 \mu \mathrm{V}$ \\
\hline \multicolumn{4}{|c|}{ Transmitter package (with two batteries): } \\
\hline & Volume & $4 \mathrm{~cm}^{3}$ & $10 \mathrm{~cm}^{3}$ \\
\hline & Weight in air & $13 \mathrm{~g}$ & $16.2 \mathrm{~g}$ \\
\hline & Weight in water & $9 \mathrm{~g}$ & $6.2 \mathrm{~g}$ \\
\hline
\end{tabular}

Table-1 Specifications of dual- and quad-channel transmitters. 
$\mathrm{A}_{1}$

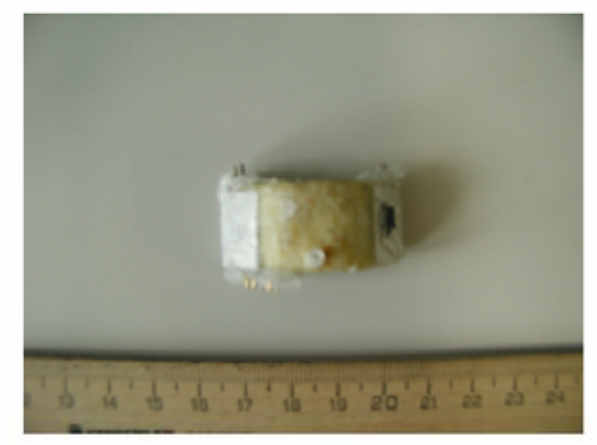

B

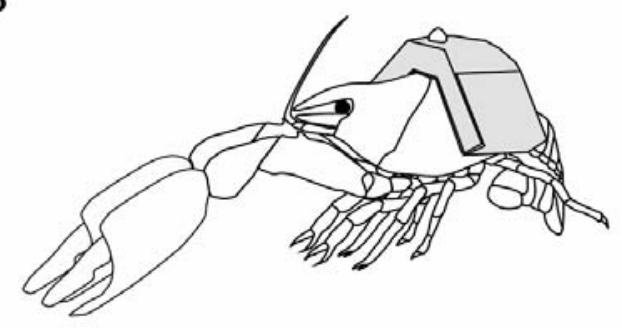

$\mathrm{A}_{2}$

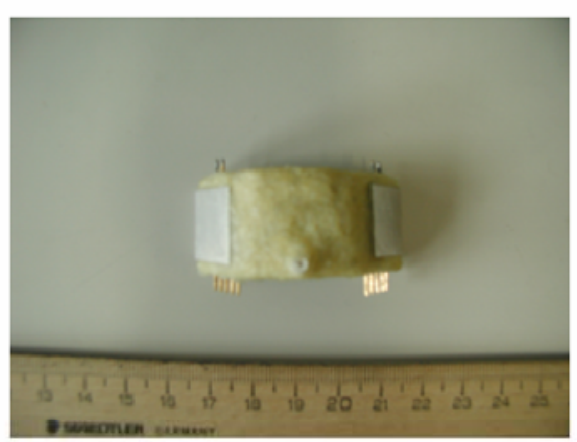

C

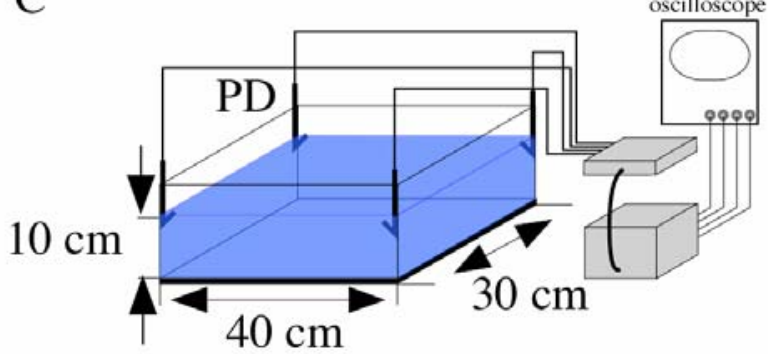

Figure-1 

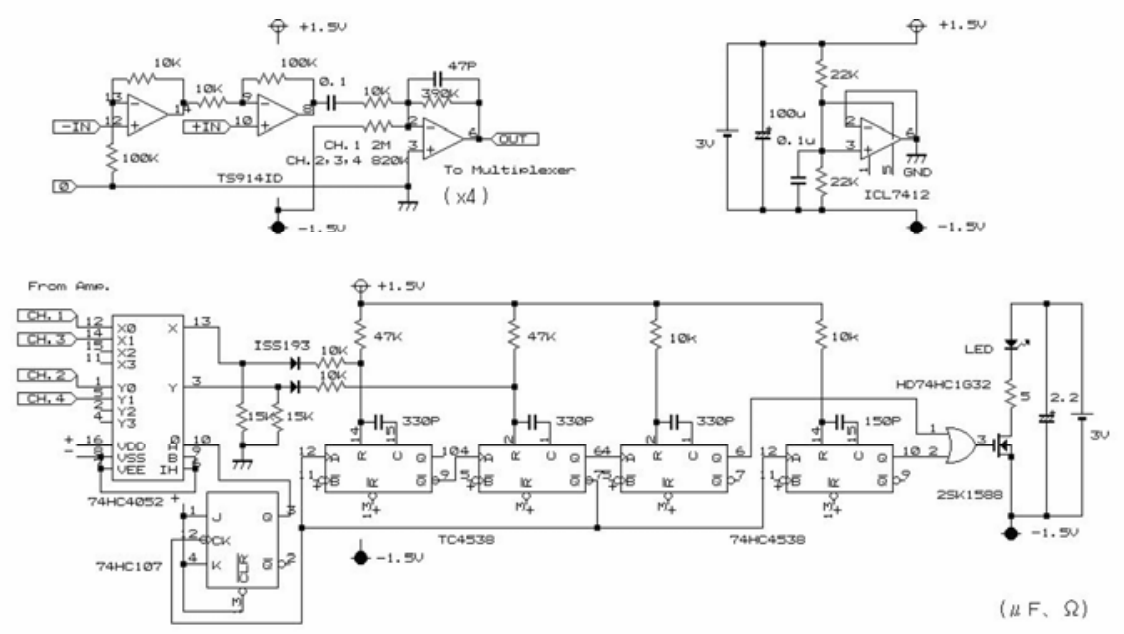

Figure-2 

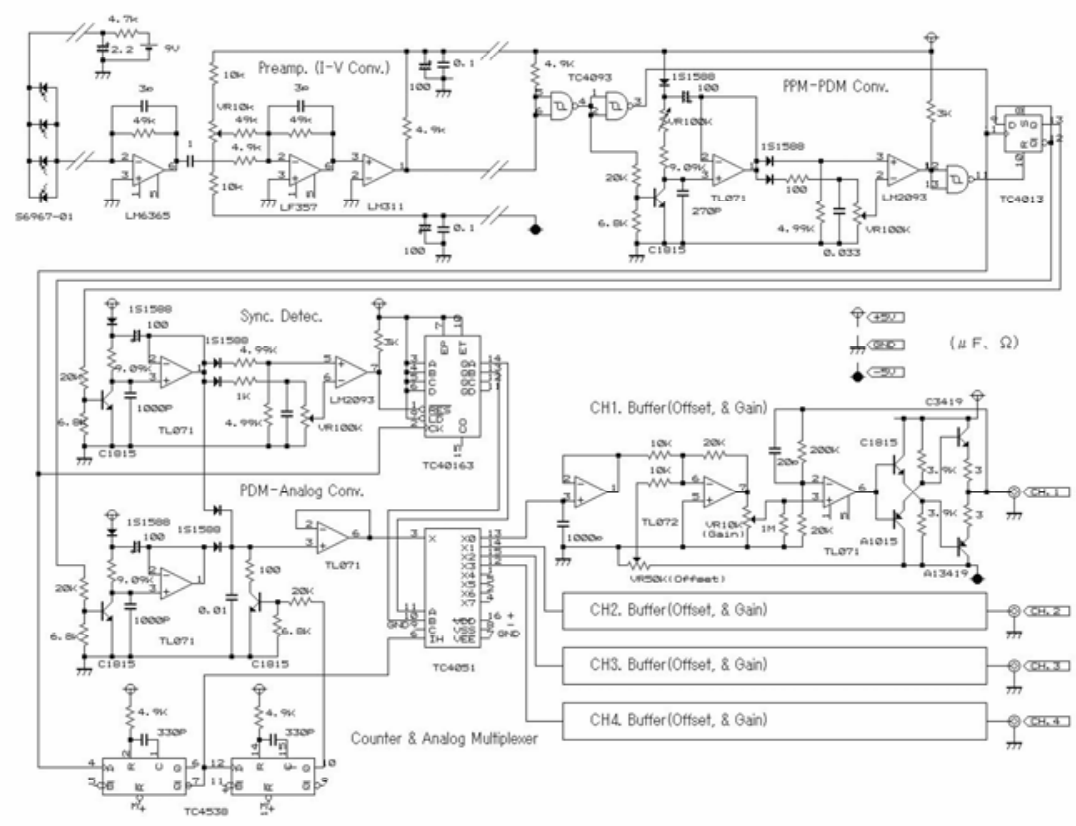

Figure-3 

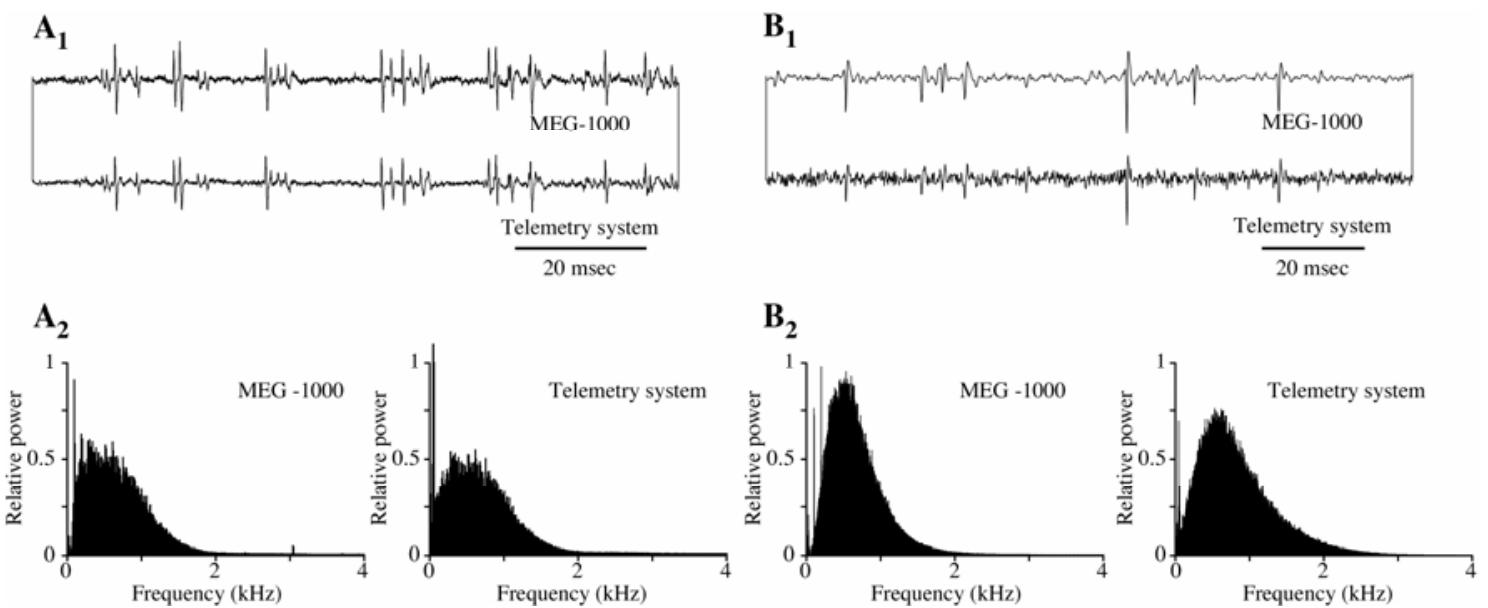

Figure-4 
A
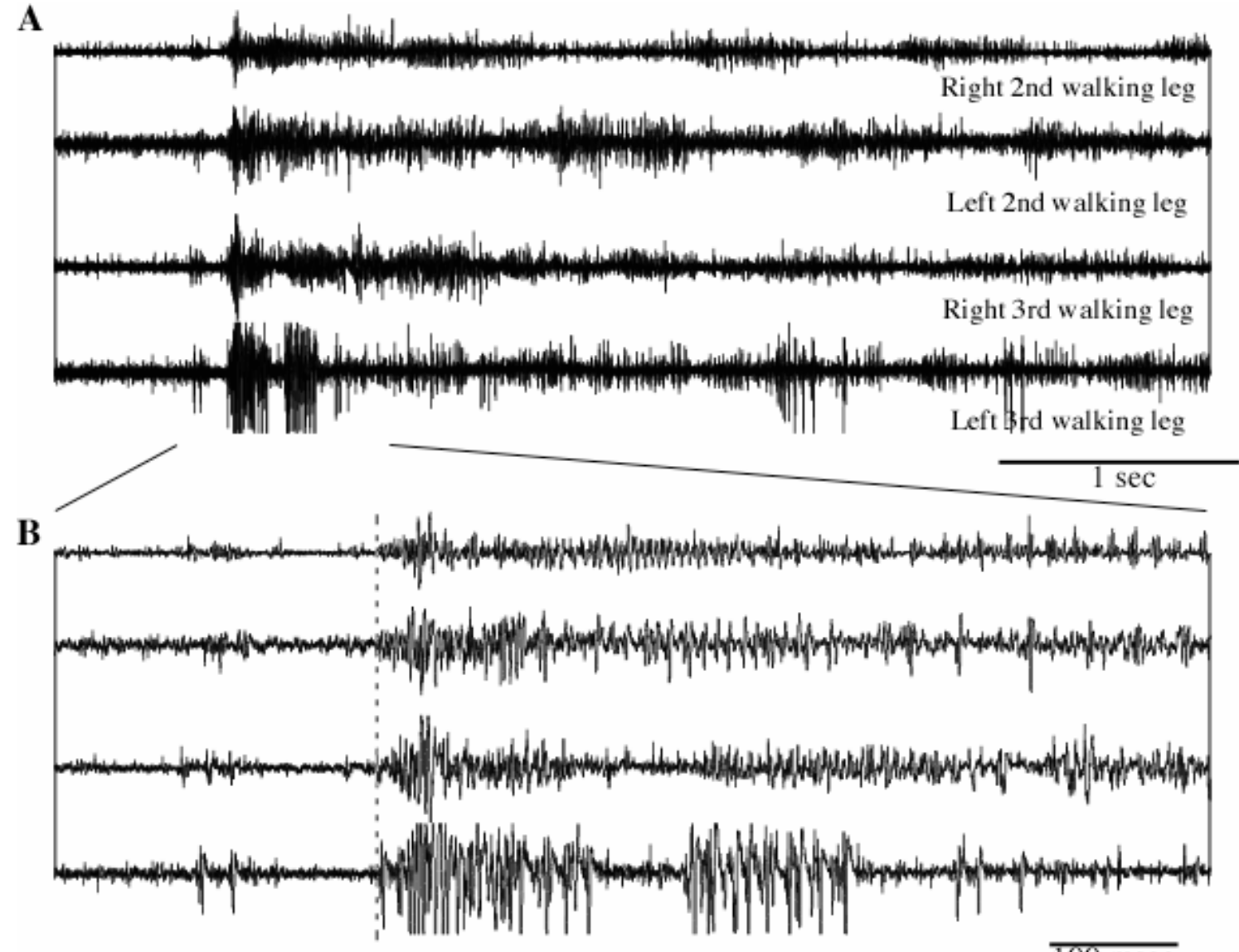

Figure-5 